\title{
A Study to Assess the Effectiveness of Video Assisted Teaching Programme on Knowledge Regarding Seizure Among Mothers of Under Five Children in Selected Community Area, Uttar Pradesh
}

\author{
Parul Verma ${ }^{1}$, Minu S.R ${ }^{2}$ \\ ${ }^{1}$ M.SC (N) Final Year Student, College of Nursing, Rama University, Kanpur, India \\ ${ }^{2}$ Asso. Professor cum HOD of Pediatric Nursing, College of Nursing, Rama University, Kanpur, India \\ Corresponding Author: Parul Verma
}

\begin{abstract}
Background: Children under five years of age are more prone to develop infection, as their immune system is immature. The study aimed to assess the level of knowledge regarding seizure disorder among mothers of under five children, to evaluate the effectiveness of video assisted teaching program regarding seizure disorder among mothers of under five children and to find out the association between the pretest knowledge with their selected demographic variables of selected community area Lucknow. Conceptual model used for the study was Rosentock's modified health belief model

Objective: To assess the pretest level of knowledge regarding seizure among mothers of under five children and assess the effectiveness of the video assisted teaching program regarding seizure among mothers of under five children and find out the association between the pretest knowledge with their selected demographic variables.

Materials and Method: The research approach was evaluative, the research design was preexperimental, a one group pre-and posttest design was used for the study. A sample was 30 mothers with children aged under five were selected through convenient sampling method on knowledge regarding seizure. It was assessed by structured questionnaire, where during the pretest the mothers of children aged under five were attended the video-assisted teaching regarding seizure. Posttest data were collected after 1 week of implementation of videoassisted teaching.
\end{abstract}

Results: The data were analyzed by using descriptive and inferential statics. The result revealed that after the intervention the mean and standard deviation of post-test knowledge was 28.8 and 2.51 being compare to pre-test 11.4 and 3.15.It indicate that there was a significant improvement in the level of knowledge of participants. The calculated t value (20.30) on analyses of the data was found to be significant at $\mathrm{p}$ value 0.05 .

Conclusion: The video-assisted teaching was effective and improved the knowledge regarding seizure among mothers of under five year children.

Keywords: Assess, Effectiveness, Video assisted teaching, Knowledge, Seizure, Mother of under five children.

\section{INTRODUCTION}

Seizures are common neurological disorders in children. It usually occurs with a temperature of $38^{\circ} \mathrm{C}$ or higher ruling out central nervous system infection, metabolic disturbance or history of a seizure. Seizure is an age-dependent response of the immature brain to the fever that enhances neuronal excitability that disposes the child to the seizures. In developed countries, up to sixty percent of children have experienced a febrile episode before the age of five. The rate of febrile children admitted to the emergency unit is $20-30 \%$ in the world and recurrence is $30 \%$. It occurs in children between six months and five years with a 
peak incidence between 12 and 18 months of age. ${ }^{1}$ Seizure is a non communicable disorder in under 5-year-old children, but at the same time, it is an alarming event in the lives of both child and parents. Lack of parent's knowledge about the nature of seizure and how they should deal with it can lead to poor management. ${ }^{2}$ Seizures have defined by The International League against Seizure (ILAE) as a seizure occurring in childhood after one month of age, associated with illness not caused by an infection of the central nervous system, without previous neonatal seizures or a previous unprovoked seizure, and not meeting criteria for other active symptomatic seizures. About one and a half million seizure events occur per year in the United States. Most seizure incidents show a geographical variation and most of it occurs between 6 months and 36 months of age, peaking at 18 months. ${ }^{3}$ Any illness with temperature more than $38^{\circ} \mathrm{C}$ can precipitate a seizure. The quickness of rise of temperature is an important factor. Certain fevers have greater prediction to precipitate a seizure. Most seizures occur within the 2 to 3 days of fever. A genetic predisposition is strongly observed. The empiric risk of seizure after one affected child is 10 percent; it rises to almost 50 percent if one parent had seizure. Most studies suggest a dominant mode of inheritance with reduced penetration. Presence of abnormal neurodevelopment, family history of seizure or persistent neuromuscular deficit should arouse a suspicion of a more sinister process. Subsequent seizures and seizure in later years are more common in this group and continuous prophylaxis may become necessary. ${ }^{4}$

Due to inadequate knowledge regarding seizure and to manage the emergency situation among mothers of under five year children, the investigator wanted to give awareness on seizure through a video-assisted teaching.

\section{LITERATURE REVIEW}

A study was conducted on seizure: inquiry about the knowledge, attitudes and concerns of the patient's mothers. The data was collected by using a prospective-based study from 126 mothers of consecutive children presenting with seizure. Among these, only $58(46 \%)$ mothers recognized the seizure. $49(39 \%)$ of them interpreted seizure as death. Others interpreted it as other causes. $85(68 \%)$ parents did not carry out any intervention prior to getting the child to hospital. The most common cause of concern among parents was the state of their child's health in the future $(n=120$, $95 \%$ ), followed by the fear of recurrence $(\mathrm{n}=83,66 \%)$, mental retardation $(\mathrm{n}=60$, $48 \%)$, paralysis $(\mathrm{n}=39,31 \%)$, physical disability $(\mathrm{n}=37,30 \%)$ and learning dysfunction $(\mathrm{n}=28,22 \%)$. In $41(33 \%)$ mothers, there were other causes of concerns too. Awareness of preventive measures was higher in mothers with high educational level $(\mathrm{P}<0.01)$. $76 \%$ of the mothers did not know anything about the necessary measures in case of recurrence. The study concluded that parental fear of seizure is a major problem, with serious negative consequences affecting daily familial life. ${ }^{5}$ A preexperimental study conducted to studied the risk factors for seizure. Children between 4 months and 6 years with a history of first or recurrent attack of seizure were included in the study. Out of 86 cases $11.62 \%$ were below 6months, $52.32 \%$ were between 6 and 12 months, $23.27 \%$ were between 13 and 18 months and $12.79 \%$ were above 18 months.58children were male and 28 were female. More than one attack within 24 hours was found in 24 children. Family history was found in 18 children male and 28 were female. More than one attack within 24 hours was found in 24 children. Family history was found in 18 children. ${ }^{6} \mathrm{~A}$ quasi experimental study was conducted on "effectiveness of paracetamol and tepid sponging and paracetamol alone in reducing fever and prevention of seizure among children" in pediatric department of the 
selected teaching hospitals. Purposive sampling method was followed and the children of age group 1-2 years were selected for the study. The maximum temperature of $37-38^{0} \mathrm{c}\left(100^{0} \mathrm{f}\right)$ was kept as a base line to initiate the intervention. Other members for the study like the nurses, parents and the care takers were selected based on the inclusion criteria. The study concluded that use of paracetamol combined with tepid sponging was more effective in bringing down the temperature than using paracetamol alone. $^{7}$

A prospective study conducted to questionnaire-based study to evaluate the knowledge, attitude and practice of mothers of under-five children suffering with febrile convulsion at the Mofid children hospital. Sample consisted of 126 mothers of children with febrile convulsion. The study result shown that most common cause of concern among parents was the state of their child's health in the future, followed by the fear of reoccurrence, mental retardation, paralysis, physical disability and learning dysfunction. Awareness of preventive measures was higher in mothers with high educational level. Majority of mothers (76\%) did not know anything about the necessary measures in case of recurrence. This study concluded that parental fear of febrile convulsion is the major problem, with serious negative consequences affecting daily familial life.

\section{MATERIALS \& METHODS}

A study to assess the effectiveness of video assisted teaching programme on knowledge regarding seizure among mothers of under five children in selected community area, Uttar Pradesh

Study Design: Pre experimental one group pre-test post-test only.

Study Location: This study was conducted at Sherpurmau, Lucknow.

Sample Size: 30 mothers of under five children.
Sampling Technique: convenient sampling technique

\section{Sampling Criteria:}

Inclusion Criteria: The mothers, who were

1. Present in the selected community area at Sherpurmau.

2. Able to read and write in Hindi.

3. Available at the time of data collection.

Exclusion Criteria: The study excluded the mothers, who were not,

1. Having children of under-five years.

2. Willing to participate in the study

\section{Data collection procedure}

The main study was conducted at Sherpurmau after getting permission from the Gram Pradhan, the researcher met the mothers. The purpose and duration of the study was explained to the mothers in rural areas and their written consent was obtained. The sample was collected by nonprobability convenient sampling with reference to the selected criteria. The questionnaire was distributed to assess the effectiveness of video assisted teaching program on knowledge regarding seizure among mother of under-five child after pretest video assisted teaching program was given. The mothers were encouraged to clarify their doubts; post test was conducted on the $7^{\text {th }}$ day to assess the effectiveness of video assisted teaching in improving the knowledge regarding seizure disorder by using the same questionnaire.

Statistical Analysis The investigator adopted descriptive and inferential statistics to analyse the data. The demographic variables were analyses by using frequency and percentage, mean and standard deviation. The effectiveness of video assisted teaching program and association between variables were analysed by using paired ' $t$ ' test and chi square test.

\section{RESULT}

The result of data analysis is organized and presented under the following broad heading: 
Parul Verma et.al. A study to assess the effectiveness of video assisted teaching programme on knowledge regarding seizure among mothers of under five children in selected community area, Uttar Pradesh

Section-A: Assessment of knowledge of the mothers of under five children according to the pretest and posttest knowledge level on seizure disorder.

Section-B: Comparison of pretest and posttest knowledge level regarding seizure among mothers of under five children
Section-C: Effectiveness of video assisted teaching program on knowledge regarding seizure among mother of under five Children.

Section-D: Association of the pretest level of knowledge regarding seizure among mother of under five Children with their selected demographic variables.

\section{Section-A}

Table 1: Description of mothers of under five children according to the pretest and posttest knowledge level on seizure disorder

\begin{tabular}{|c|l|c|c|c|c|}
\hline \multirow{2}{*}{ Sr. No } & Level of Knowledge & \multicolumn{2}{|c|}{ PRETEST } & \multicolumn{2}{c|}{ POSTTEST } \\
\cline { 2 - 6 } & & Frequency & \% & Frequency & $\%$ \\
\hline 1 & Inadequate(Below 8) & 4 & 13.33 & 0 & 0 \\
\hline 2 & Moderate adequate (9-16) & 24 & 80 & 0 & 0 \\
\hline 3 & Adequate (Above 16) & 2 & 6.67 & 30 & 100 \\
\hline
\end{tabular}

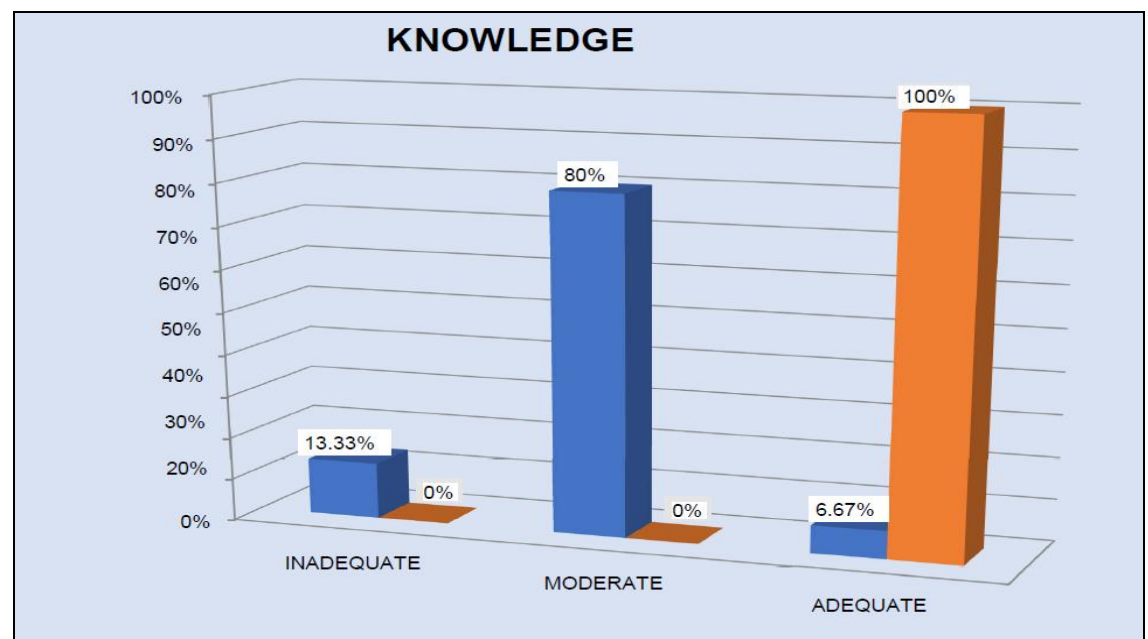

Fig.1: Bar diagram shows percentage wise distribution of pretest and posttest knowledge level on seizure of mothers of under five children

Table-1 and fig.1shows that, the pretest and posttest level of knowledge. Majority $24(80 \%)$ of mothers of under five children had moderate adequate knowledge, $4(13.33 \%)$ had inadequate knowledge, 2(6.67\%) had adequate knowledge in pretest but in the posttest majority $30(100 \%)$ of mothers of under five children had adequate Knowledge. The above finding summarizes that, the video assisted teaching has significant beneficial effect in the level of knowledge among mothers of under five children.

\section{Section-B}

Table 2 Shows comparison of mean pretest and posttest knowledge level on seizure disorder among mothers of under five children. The post test mean score (28.8) was high when compared to the pretest mean (11.4) score of knowledge.

Table.no.2: Comparison of pretest and posttest knowledge level regarding seizure among mothers of under five childrens.

\begin{tabular}{|c|c|c|c|c|c|}
\hline S.No & Knowledge & Mean & $\begin{array}{c}\text { Mean } \\
\text { Difference }\end{array}$ & $\begin{array}{c}\text { Mean } \\
\text { Percentage }\end{array}$ & $\begin{array}{c}\text { Standard } \\
\text { Deviation }\end{array}$ \\
\hline 1 & PRETEST & 11.4 & & $38 \%$ & 3.15 \\
\hline 2 & POSTTEST & 28.8 & 17.4 & $96.2 \%$ & 2.51 \\
\hline
\end{tabular}




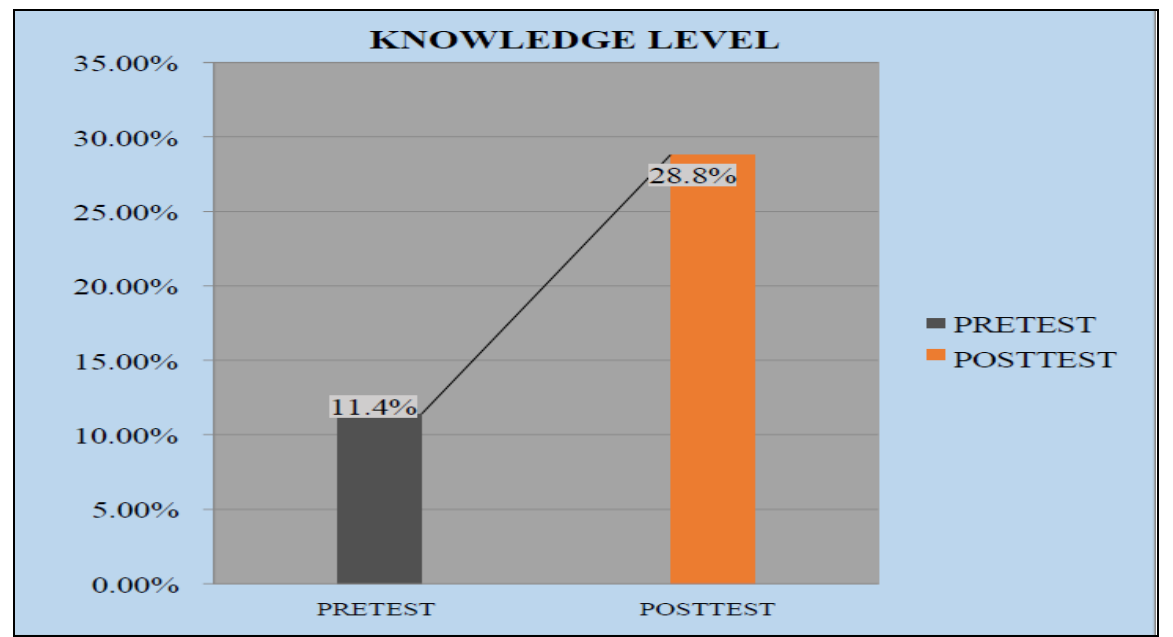

Fig.2: Bar diagram shows percentage wise distribution of mothers of under five children according to their comparison of pretest and posttest knowledge level

\section{Section-C}

Table 3 shows that the pretest mean score is 11.4 and mean percentage $38 \%$ and posttest mean score is 28.8 and mean percentage $96 \%$. The calculated $\mathrm{t}$ value 20.3098 is significant at 0.05 level. The finding implied that the video assisted teaching program had significant effect in the improvement of mother's knowledge regarding seizure disorder of under-five children. Hence, the formulated research hypothesis $\mathrm{H}_{1}$ was accepted and $\mathrm{H}_{01}$ the null hypothesis was rejected.

Table.no.3: Mean, mean percentage, $t$ test value of structured knowledge questinnior.

\begin{tabular}{|c|c|c|c|c|}
\hline S.No & Knowledge & Mean & $\begin{array}{c}\text { Mean } \\
\text { Percentage }\end{array}$ & $\begin{array}{c}\text { PAIRED } \\
\text { 't' TEST }\end{array}$ \\
\hline 1 & PRETEST & 11.4 & $38 \%$ & 20.3098 \\
\hline 2 & POSTTEST & 28.8 & $96 \%$ & \\
\hline \multicolumn{6}{|c}{$* 05$ level of significant } \\
\hline
\end{tabular}

\section{Section-D}

The association of the pre test score of mother's knowledge with selected demographic variables like age of mother, type of family, education of mother, occupation of mother, source of health information, sex of child, number of living child, monthly income, religion, previous history, previous knowledge about seizure. Here calculated value of chi square was less than table value at 0.05 level of significance. So, there was no significant association exist between the variables with their knowledge. Hence $\mathrm{H}_{2}$ was rejected and $\mathrm{H}_{02}$ the null hypothesis was accepted

\section{DISCUSSION}

- Demographic variables of mothers of under five Children.

- Assessment of mothers of under five children according to the pretest and posttest knowledge level on seizure disorder.

- Comparison of pretest and posttest knowledge level regarding seizure among mothers of under five children.

- Effectiveness of video assisted teaching program on knowledge regarding seizure among mother of under five Children.

\section{Demographic variable of mothers of under five children}

The demographic variable of considered in the present study included variables like age, gender of child, type of family, religion of mother, educational status, occupation, monthly income of family, number of children, source of information, previous history of seizure, previous knowledge received about seizure. Out of 30 samples age, majority12 (40\%) were $26-30$ years, $8(26.66 \%)$ were age between $31-35$ years, 5(16.67\%) were between $20-25$ years and $5(16.67 \%)$ were above 35 years. In context to gender of child that majority is $18(60 \%)$ male child and female child $12(40 \%)$. In context to type of the family that majority $19(63.33 \%)$ a had joint family, $11(36.67 \%)$ had nuclear family 
and no one had single parent family. In context religion of mother majority 23(76.67\%) had Hindu, 7 (23.33\%) had Muslim and there was no Christian and others. In context to educational status majority $16(53.33 \%)$ had Intermediate 8 (26.67\%) had Secondary 4(13.33\%) had Graduate and 2(6.67\%) are Primary. In context to occupation majority 20 $(66.67 \%)$ are Housewife $8(26.67 \%)$ are daily wages $2(6.66 \%)$ are private employee and no any government employee. Regarding income of the family majority $17(56.67 \%)$ had <Rs.5000 per month, $6(20 \%)$ had Rs.5001-Rs.10, 000 per month, $5(16.67 \%)$ had Rs.10001-Rs.15,000 per month, 2(6.66\%) had $>15,000$ per month. Regarding the number of living children majority $11(36.67 \%)$ mothers having three children, $9(30 \%)$ mothers having two children, $6(20 \%)$ mothers having one children, 4(13.33\%) mothers having more than three children. In context to source of information majority $13(43.33 \%)$ mothers were having knowledge from Health care worker, $7(23.33 \%)$ mothers were having knowledge from family members, 6 (20\%) mothers were having knowledge from mass media, and 4(13.33\%) mothers were having knowledge from neighbors and friends. Regarding previous history of seizure disorder in family majority $28(93.33 \%)$ had no previous history in family, $2(6.67 \%)$ had having previous history of seizure disorder in family. Regarding previous knowledge about seizure majority was $28(93.33 \%)$ had having no previous knowledge, 2(6.67\%) had having previous knowledge about seizure disorder.

A similar previous study was conducted, 80 children aged from 9 months to 5 years with their first seizures (case group) were compared with 80 children with fever without seizure (control group) based on seizures-associated risk factors in 2007 80 children with seizures 53 cases $(66 \%)$ were male and 27 (34\%) females whereas in control group the similar figures were 36 cases (45\%) and $44(55 \%)$ for males and females, respectively. Statistically, a significant difference was found between two groups regarding the gender $(\mathrm{p}=.01){ }^{8}$

Assessment of mothers of under five children according to the pretest and posttest knowledge level on seizure disorder.

In pre test $24(80 \%)$ were moderate adequate, 4(13.33\%) inadequate and 2(6.67) having adequate knowledge regarding seizure disorder. In pre test mean was 11.4, SD 3.15 and mean percentage was $38 \%$. This reveals that majority of mothers of under five children had moderate adequate knowledge. And in the post test, Majority $(100 \%)$ had adequate knowledge. The post tests mean score was increased to 28.8 and mean percentage 96 . The post test mean score (28.8) was higher than pretest.

A similar previous study was conducted among 60 mothers of under five children. In pre test $48(80 \%)$ were inadequate, $12(20 \%)$ moderate and no one having adequate knowledge regarding seizure disorder. In pre test mean was 11.55 , SD 3.59 and mean percentage was 38.5. This reveals that majority of mothers of under five children had inadequate knowledge. In the post-test majority of them had $45(75 \%)$ adequate knowledge, $15(25 \%)$ moderate and no one had inadequate knowledge regarding seizure disorder. In post test mean was 24.41, SD 3.2 and mean percentage is $81.37 .^{8}$

\section{Comparison of pretest and posttest knowledge level regarding seizure among mothers of under five children-}

Compression of mean, SD of assess the effectiveness of video assisted teaching program on mothers of under five children reveals that The post test mean score (28.8) and S.D 2.51 was high when compared to the pretest mean (11.4) score of knowledge and SD 3.15. Mean difference is 17.4.

A similar study was conducted to mean knowledge score 24.41 obtained by the subject in post test was higher than the mean knowledge score 11.55 in the pre test and with the improvement score was 12.86 . 
There was significant difference between pre and post test knowledge score. ${ }^{9}$

\section{Effectiveness of video assisted teaching program on knowledge regarding seizure among mother of under five Children-}

In the post test, Majority (100\%) had adequate knowledge. The post test mean score was 28.8 and mean percentage 96 . The post test mean score (28.8) was high when compare to pre test mean (11.4).The calculated paired " $\mathrm{t}$ " test value 20.3098 was significant at 0.05 level. Calculated value was greater than table value at 0.05 level of significance, which shows there was a significant difference between the pretest and post test knowledge of mothers of under five children. Hence, the formulated research hypotheses. $\mathrm{H}_{1}$ was accepted. This shows that there was a significant improvement in knowledge of mothers of under five child regarding seizure disorder after administration of video assisted teaching, so the video assisted teaching was effective in improving knowledge of mothers of under five children on seizure disorder.

A similar study was conducted to mean knowledge score 24.41 obtained by the subject in post test was higher than the mean knowledge score 11.55 in the pre test and with the improvement score was 12.86. There was significant difference between pre and post test knowledge score with the $\mathrm{t}$ value of 37.6 found to be significant at $\mathrm{p}<0.01$ level. This indicates that the structured teaching program was highly effective in enhancing the knowledge of mothers of under five children regarding management of seizure. Hence the research hypothesis was accepted. ${ }^{8}$

\section{RECOMMENDATION}

On the basis of the findings of the study, following recommendations put forward for further research.

- A similar study can be replicated on a large sample to generalize the findings

- A comprehensive study can be conducted to assess the effectiveness of video assisted teaching between rural and urban mothers of under five children.

- A similar study can be conducted in hospital setting.

- A experimental study can be conducted with control group for comparison.

\section{CONCLUSION}

Seizure among children aged under five is a common problem and usually causes anxiety and fear among parents, especially mothers. Seizure can be managed by health education and training to improve the mother knowledge regarding seizure and reduce the frequency of symptoms among children aged under five.16 The result of the study proves that video-assisted teaching was effective and improved knowledge regarding seizure among mothers of under five children.

\section{Acknowledgement: None}

\section{Conflict of Interest: None}

\section{Source of Funding: None}

\section{Ethical Approval: Approved}

\section{REFERENCES}

1. El Sayed HI. Recognition of Parent's Knowledge, Attitude and Practice Regarding Seizures in Children Under-Five. American Journal of Nursing. 2020;8 (1):72-81.

2. Shibeeb NF, Altufaily YA. Parental knowledge and practice regarding seizure in their children. Medical Journal of Babylon. 2019; 16(1):58-64.

3. Motala L, Eslick GD. Prevalence of recent immunization in children with seizures. World journal of clinical pediatrics. 2016 Aug 8; 5(3):301.

4. Parthasarathy A, Menon PS, Nair MK. IAP Textbook of pediatrics. JP Medical Ltd; 2019 Feb 4.66-8

5. Huang MC, Liu CC, Chi YC, Thomas K, Huang CC. Effects of educational intervention on changing parental practices for recurrent febrile convulsions in Taiwan. Epilepsia. 2002 Jan; 43(1):81-6. 
Parul Verma et.al. A study to assess the effectiveness of video assisted teaching programme on knowledge regarding seizure among mothers of under five children in selected community area, Uttar Pradesh

6. Khwaja GA, Duggal A, Kulkarni A, Chaudhry N, Gupta M, Chowdhury D, Bohra V Recurrent prolonged fugue states as the sole manifestation of epileptic seizures. Annals of Indian Academy of Neurology. 2013 Oct; 16(4):561.

7. Murata S, Okasora K, Tanabe T, Ogino M, Yamazaki S, Oba C, Syabana K, Nomura S, Shirasu A, Inoue $\mathrm{K}$, Kashiwagi $\mathrm{M}$. Acetaminophen and febrile seizure recurrences during the same fever episode. Pediatrics. 2018 Nov 1; 142(5).

8. Deepthi SJ. A Study to assess the effectiveness of structured teaching programme on knowledge and practice of mothers regarding care of children with seizure disorder in Vilankurichi,
Coimbatore (Doctoral dissertation, PPG College of Nursing, Coimbatore

9. George J. A Study To Assess The Effectiveness Of Structured Teaching Programme Regarding Knowledge On Management Of Febrile Convulsion Among Mothers Of Under Five Children In Rajarajeswari Medical College And Hospital, Bangalore.

How to cite this article: Verma P, Minu S.R. A study to assess the effectiveness of video assisted teaching programme on knowledge regarding seizure among mothers of under five children in selected community area, Uttar Pradesh. International Journal of Research and Review. 2021; 8(4): 53-60. DOI: https://doi.org/ 10.52403/ijrr.20210409 